\title{
Espiritualidad y teología. A propósito del libro de Gustavo Gutiérrez "Beber en su propio pozo"
}

\section{JON SOBRINO}

Centro de Reflexión Teológica, San Salvador

En la actualidad el tema de la espiritualidad ha recobrado un inusitado interés, pero no sólo en la lglesia ni sólo, como era usual, entre quienes en ella se dedican a la perfección, sino antes que nada en el mundo. La historia actual, con su crisis, cuestionamientos, posibilidades y exigencia a construir un futuro humano interpelan a los hombres y a la humanidad como tal. Esta interpelación puede ser desoída, manipulada o pervertida; pero para los más lúcidos vuelve a resonar la pregunta por lo que son y deben ser, por lo que esperan y pueden esperar, por lo que hacen y deben hacer; desde la misma historia surge la llamada a responder por la verdad de la historia y por la propia verdad, a configurarla sin dejarse dominar por ella ni deslizarse pasivamente en ella.

Esta es tarea perenne, pero inevitable y urgente en momentos de crisis y de des-quiciamientos, cuando los antiguos quicios no aguantan ya el peso del edificio. Crear nuevos quicios sobre los que la historia gire y gire bien y en la que los hombres puedan vivir o volver a vivir como seres humanos, supone muchos elementos. Pero integrarlos todos ellos adecuadamente no es sólo cosa de ciencia o ideología, sino cosa de espiritu. A ese ser-humano con espíritu que responde a lo que la realidad tiene de crisis y de promesa y que unifica los diversos elementos de la realidad para que ésta sea en definitiva más promesa que crisis es a lo que llamamos espiritualidad. Esta descripción de la espiritualidad puede parecer excesivamente vaga, pero es importante para poner en la pista correcta a) hablar de ella y no reducirla, consciente o inconscientemente, a algo regional, ni reducir su ámbito a lo inmateral o interiorista.

También en la Iglesia surge con fuerza la pregunta por la espiritualioad. Esto se debe a que la lglesia participa -io quiera o no- en la historia actual y sus exigencias, y a que dentro de la misma Iglesia se ha producido un desquiciamiento con la novedad del Vaticano II y Medellin. No se puede negar la existencia de nuevos elementos doctrinales, teológicos, pastorales y litúrgicos junto a los que la tradicion ha transmitido; no se puede negar que la sintesis -en teoria y mucho más en la práctica - tiene sus dificultades y que se ha realizado de diversas maneras, que en unos está más presente el gozo de lo nuevo 
para integrar en ello lo antiguo y en otros la añoranza de lo antiguo ante el temor de lo nuevo.

El mosaico eclesial, hecho de tantas piezas y de tantos colores, se desperdigó y hay ahora que volver a rehacerlo. Ante tarea tan exigente y los peligros que puede conllevar, se puede optar por una reconstruccion en base a la seguridad doctrinal y a la imposición administrativa-jerárquica; pero, aunque doctrina y administración sigan siendo necesarias e importantes, no es ésta la forma adecuada de reconstruir el edificio. Para ello se necesita espirilu y mucho espiritu que crealivamente sintetice los diversos elementos de los que está hecha la Iglesia: trascendencia e historia, ministerio jerárquico y pueblo de Dios, fe y práctica, etc. Por ello hay en la Iglesia, entre los más lúcidos y conscientes, no solo interes, sino un verdadero clamor por espiritualidad. Con ello están afirmando la imperiosa necesidad de ser y saberse creyentes y pueblos cristianos en el mundo de hoy, sacramento de salvación en el mundo. Cómo realizar eso es cuestión de espiritu y por ello se busca aquella espiritualidad que sintetice el ser hombres y el ser creyentes, el salvar y ser salvados, el servir a Dios y remitirse a Dios.

Por estas razones fundamentalmente, pero también por otras más específicas, se ha suscitado también en la teología un serio interés por la espiritualidad. En este proceso que dura ya varios años se comenzó por constatar que una teologia doctrinal, puramente explicativa y deductiva, no era ya adecuada al estallido de la realidad en la historia y en la Iglesia, pues ese estallido remitía a los hombres a lo que es pre-doctrinal y globalizante. Una teologia puramente doctrinal se hizo irrelevante; $e$ incluso la verdad que proclamaba para mantener la identidad de la fe se convirtio en verdad genérica, pero no en la verdad concreta que toda teología basada en el presupuesto de la continuada acción de Dios debe elaborar. El repartir la identidad y la relevancia de la teología entre los tratados dogmáticos por una parte y los de moral, pastoral y espiritualidad por otra, no resolvib el problema porque éste no consistía en la organización formal de los contenidos de la teologia, sino en el talante que la informa en su totalidad.

En este contexto, la renovación de la teología ha consistido no sólo en dedicar atención a contenidos olvidados, sino en tratar aquellos que por su misma naturaleza comunican un determinado espíritu. Por mencionar un importante ejemplo, el reino de Dios como realidad objetiva y sus correlatos de esperanza utópica y práctica transformadora como realidades subjetivas, se han hecho cada vez más contenidos y talantes de toda la teología. El cambio fundamental no consistio en afiadir el 'reino de Dios' a otros contenidos ya sabidos, sino en la exigencia objetiva al sujeto de la teologia de analizarlo con un espiritu nuevo correspondiente al objeto y a of recerlo con espiritu a sus destinatarios. En esto está el cambio fundamental con respecto a una teologia puramente doctrinal; el quehacer teológico debe estar todo él transido de esperanza y de exigencia de práctica cristiana, tanto cuando se habla explicitamente del reino de Dios como cuando se habla de olros contenidos.

$\mathrm{Al}$ asumir un talante esperanzado y práxico la teologia se fue haciendo ya 
teología espiritual. Lo que ha ocurrido después es que la misma teología se ha hecho consciente de su estatuto espiritual, por acción u omisión. Está tratando temas convencionalmente espirituales, pero sobre todo está reconociendo la necesidad de que debe ser hecha con espíritu y con el Espiritu de Dios para comunicar espíritu y el Espiritu de Dios. Por recordar algunas afirmaciones de teólogos europeos más lúcidos, ya en 1969 Urs von Balthasar, hablando precisamente de la incipiente teologia política, la reinterpretaba como redescubrimiento de la "espiritualidad bíblica" y añadía: "No cortemos las alas a una generación que ha tenido la sensibilidad para descubrir como insoportable la separación entre teologia y espiritualidad, entre contemplación y acción, entre Iglesia y mundo." K. Rahner, aludiendo al ejemplo de Sto. Tomás, abogaba por superar "aquella horrible división que se puede observar en la teologia posterior, entre teología y vida espiritual."2 J.B. Metz, promotor de la teologia política, ha hablado de la "mistica y la política del seguimiento." 3 Estas citas son sólo indicativas, pero muestran la necesidad de integrar la espiritualidad en la teología como una de sus dimensiones esenciales.

Esto es también lo que ha sucedido y está sucediendo en la teología de la liberación (TL). Es evidente que desde sus orígenes esta teología profesa un talante utópico y práxico y de parcialidad hacia los pobres, pues desea ser y tiene su razón de ser en la liberación integral de las mayorias pobres. Pero esto no ha sucedido reductivamente, como acusan algunos, sino en complementaridad con el talante espiritual. "Desde los primeros pasos de la teologia de la liberación la cuestión de la espiritualidad (precisamente el seguimiento de Jesús) constituyb una profunda preocupacion.' Una cosa es que la TL no explicitase en sus inicios una espiritualidad - aunque tampoco hayan faltado trabajos sobre ella, ya en los comienzos - y otra cosa es que no naciera con una talante espiritual. Claramente se dijo que para la liberación no bastan las categorías puramente teóricas: "Es necesario una actitud vital, global y sintética, que informa la totalidad y el detalle de nuestra vida. Una espiritualidad. ${ }^{\prime 6}$ En los orígenes está presente el "encuentro con el Señor" en los pobres y la "vivencia de gratuidad." El que en el origen de la TL haya espíritu y espiritualidad fue una necesidad, comprensible por lo dicho anteriormente, pues se trataba de hacer una nueva sintesis creativa del ser cristiano ante la novedad del continente latinoamericano: lo insoportable de lo antiguo y la aparición de lo nuevo con fuerza incontenible.

Lo que estaba en el origen se ha ido explicitando cada vez más de forma teológica. Por citar sólo dos ejemplos, en 1979 siete revistas latinoamericanas publicaron simultáneamente un número monográfico sobre "Espiritualidad de la Liberacion." 18 Como se dice en la presentación, se trata "de un fenomeno que ha estado pervadiendo la vida cristiana de los cristianos comprometidos en la renovación de esta tierra crucificada. Sólo una 'espiritualidad' es capaz de dar razón de la dinámica del cristianismo latinoamericano y de su fecundidad creciente." En 1982 se publicb en Costa Rica el libro Espiritualidad y liberación en América Latina ${ }^{10}$ en el cual doce autores expusieron los diversos aspectos de la espiritualidad de la liberacion. En un apéndice se aducen 74 titulos aparecidos sobre espiritualidad desde la perspectiva de la liberación. En la 
introducción vuelve a repetirse que la ternática de la espiritualidad "nace como consecuencia de una vida comprometida en la praxis liberadora de y desde el pobre"ll; y, a la inversa, que éste es "el lugar desde el que se vive la experiencia de Dios y la vida según el Espíritu."12

La TL, por lo tanto, se ha ido haciendo cada vez más también teología espiritual. La espiritualidad le es una dimensión tan primigenia y necesaria como la liberación, y ambas se reclaman mutuamente. Así lo reconocen muchos en la actualidad, ${ }^{13}$ aunque desafortunadamente no lo haya observado la Instrucción sobre algunos aspectos de la Teologia de la Liberación. Creemos además que la espiritualidad se está comprendiendo no sólo como una dimensión de la teologia, sino como dimensión integradora de toda ella. Redescubiertas y asumidas por la TL, las dimensiones de corporeidad, socialidad, praxicidad y utopicidad del hombre, se las desea integrar a todas ellas en la espiritualidad. Con ello no se hace más que proseguir la intuición paulina de presentar al hombre nuevo como el hombre espiritual. Espiritualidad aqui poco tiene que ver con inmaterialidad o con regionalidad de la vida cristiana; tiene que ver con toda ella. "Hombres espirituales, desde el punto de vista cristiano, son aquellos que están llenos del Espiritu de Cristo y lo están de una manera viva y constatable, puesto que la fuerza y vida de ese Espíritu invade toda su persona y toda su acción."14 Con esto tiene que habérselas la teologia, con presentar esa sintesis cristiana y con propiciarla.

Lo que pretendemos hacer a continuación es 1) presentar la espiritualidad de la TL a propósito del libro de G. Gutiérrez Beber en su propio pozo, y 2) reflexionar sobre la TL como una teología espiritual.

\section{La espiritualidad de la TL: "Beber en su propio pozo"}

Este último libro de GG es importante. Por su autor en primer lugar, pues GG está siempre atento al desarrollo de la TL y, más importante, al desarrollo de los procesos de liberación, de la vida de la Iglesia y de la relación de ambas cosas con la TL. Es importante también porque esclarece, aunque sea de forma indirecta, el debate sobre el principio inspirador y determinante de la TL. $\mathrm{Y}$ es importante por el tema: la espiritualidad. En el libro se ofrece una sintesis de la propia teologia espiritual de GG, la cual recoge las reflexiones de otros autores. De esta síntesis se dice que es provisional (p. 139), no sólo por lo que de teóricamente puede tener de inacabada, sino por la naturaleza misma del asunto, pues la espiritualidad por definición está siempre remitida a la historia real y su novedad.

Como toda sintesis ha necesitado tiempo. GG afirma que el tratamiento explícito de la espiritualidad en este libro es "el pago de una vieja deuda" (p. 11). Y si no se ha hecho antes no es sólo porque la TL dedicó sus primeros esfuerzos teóricos al esclarecimiento de su propio titulo, es decir, de la naturaleza de la liberación y de la teología, sino por la misma naturaleza del asunto. La espiritualidad es algo real que necesita tiempo para constituirse en su realidad y no sólo en su conceptualidad; la TL por otra parte, reflexiona sobre lo real en la medida en que va ocurriendo, aunque doctrinalmente pueda poseer conceptos previos a la realización. Por ese doble motivo, el tratamiento teológico 
de la espiritualidad ha necesitado tiempo; pero por ello también, como dice acertadamente P. Trigo, "no se trata, pues, de ideologia ...sino de teoria (es decir, comprension de una praxis)... Por eso el libro no pudo ser escrito antes." 15 Como contrapartida a la tardanza se ofrece la realidad de la espiritualidad y un lenguaje teórico-real y no sólo teórico-conceptual.

Esto es lo que se indica con claridad en el titulo, importante y sugerente como todos los de GG: Beber en su propio pozo. Más allá de la belleza de la expresion, hay que comprenderlo bien, pues en ello está en juego el contenido, el método y el talante fundamental del libro. La afirmación fundamental es que en América Latina existe un pozo con agua de vida, que lo han ido llenando con su fe, su esperanza, con su compromiso y con su gozo, con sus lágrimas y su sangre muchas veces, los cristianos del pueblo pobre que se han comprometido con la liberacion. Porque existe ese pozo de vida cristiana puede haber espiritualidad; porque esa vida cristiana es novedosa puede haber una nueva espiritualidad; y porque muchos beben de ese pozo - los mismos pobres en, primer lugar, pues es su pozo, y quienes se han acercado y comprometido con ellos- hay una espiritualidad. Por esta razón, el libro no es, como ocurre con frecuencia, un libro sobre la historia de espiritualidades del pasado, sino sobre la realidad actual de la espiritualidad. Por ello también su método es fundamentalmente narrativo. Aunque el libro esté estructurado de forma sistemática, en su nervio es teologia narrativa; sistematiza teóricamente lo que narra y narra lo que existe. Como lo que existe en un pueblo con fe, esperanza y caridad, el talante del libro es gozoso; ofrece una buena noticia. Habla de espiritualidad no sólo en el contexto de sus costosas exigencias, sino como invitación a realizarla, a recobrar asi la más profunda identidad del ser hombre y del ser cristiano.

La espiritualidad es presentada como sintesis de la vida cristiana y en relación esencial a la liberación. No entra, pues, por la puerta falsa en la teologia, sino con todo derecho. En el libro aparece con claridad que no puede haber espiritualidad sin liberación, lo cual está en la intuición original de la TL. Lo que se explicita ahora más detalladamente es que no puede haber liberación total sin espiritualidad y que ésta potencia aquélla.

Veamos ahora de forma sistemática lo más importante del libro, aquellos aspectos ya tratados por otros autores latinoamericanos, lo cual muestra que la espiritualidad es algo ya adquirido en la TL, y especialmente los más novedosos del libro de GG. ${ }^{16}$

\subsection{Espiritualidad como totalidad de vida cristiana e histórica}

Si en algo se insiste en la TL es que la espiritualidad es totalidad en el sujeto, personal y grupal, remitido a la totalidad de la historia. No es fácil por ello comenzar a hablar de espiritualidad. En el libro de GG se ofrecen dos puntos de partida unificados que permiten dos marcos teóricos unificados para comprender la dimension de totalidad de la espiritualidad. Estos son la irrupción del Seflor que invita a y exige un seguimiento y la irrupción del pobre que invita a y exige la liberación. Cuál sea la relación entre ambas experiencias y totalidades, qué prioridad lógica tenga una sobre la otra, se irá analizando des- 
pues. Lo importante ahora es ver desde el principio ambas cosas en unidad, aunque metodologicamente haya que tratarlas por separado.

1.l.I El seguimiento de Cristo. "Seguir a Jesús define al cristiano. Reflexionar sobre esta experiencia es el tema central de toda teologia" (p.11). Con estas palabras comienza el libro y a ellas regresa para definir la espiritualidad. El seguimiento no es algo regional o ascético como si Jesús, sus aclitudes, sus prácticas y sus virtudes fuesen algo a imilar una vez ya constituido el sujeto cristiano. La verdad es más bien la contraria. Seguimiento de Jesús es sinónimo de totalidad de vida cristiana; $y$, por la propia naturaleza de ser seguimiento y no pura imitación, es el proceso de llegar a realizar la vida cristiana. Desde estos dos aspectos, totalidad y procesualidad, se define la espiritualidad como "un caminar según el Espiritu de Cristo" (pp. 59,73,85). Esta definición es explicitada de forma trinitaria en el capitulo II: "Encuentro con Cristo, vida en el Espíritu, ruta hacia el Padre, son, nos parece, las dimensiones de todo camino espiritual según la Escritura" (p. 58).

Este enfoque trinitario de la espiritualidad tiene importantes consecuencias. Formalmente se dice no solo que la espiritualidad es, sino que tiene que ser un caminar en la historia. Para ello se nos ha dado la normatividad fundamental de Jesús,se nos abre el futuro del Padre, pero entre ambas cosas existe un caminar, procesual y cambiante, en el Espíritu. De ahí se sigue que espiritualidad no puede ser simple imitación de lo ya dado y prescrito a priori, sino algo siempre a rehacer; que a la espiritualidad le compete por esencia la novedad, aunque ésta haya de ser juzgada según el espiritu de Jesús; que esa novedad está relacionada con la novedad de la historia, antes de ser novedad biográfica en el sujeto, porque en esa historia sigue actuante el Espiritu de Dios que se manifiesta en los signos de los tiempos. Espiritualidad no es otra cosa que participar en la historia de Dios mismo, en cuanto éste la ha asumido en Cristo y en el Espiritu, y hacerla según Dios. En esto consiste el 'seguimiento' de Cristo.

Pero el enfoque trinitario tiene también consecuencias para el contenido fundamental de la espiritualidad. Indudablemente hay que analizar en detalle quién es ese Dios trinitario y cuál es su voluntad para la historia. Pero se puede decir a priori - y mucho más teniendo en cuenta la situación del continente latinoamericano- que ésa es la vida. El Padre es el origen y plenificador de la vida; el Hijo es el que ha venido a traer vida y vida en plenitud; el Espíritu es señor y dador de vida. Que Dios sea vida y que la propicie trinitariamente es fundamental para la espiritualidad. En América Latina esto se traduce, como veremos, en la voluntad de Dios de propiciar la vida de los pobres. Baste recordar aqui la conocida frase de Mons. Romero: Gloria Dei vivens pauper. Lo que GG aflade también desde el principio, tal como lo ha elaborado la TL, es que la voluntad de Dios para la vida se realiza en presencia de la muerte y de una voluntad de muerte; el Dios de la vida coexiste con las divinidades de la muerte y ambos están en pugna. Esto pone a la espiritualidad desde el principio ante una alternativa fundamental. El cristiano está ante dos caminos, "uno que esté marcado por la muerte (el pecado y la ley), el otro por la vida (la gracia y la libertad)" (p. 109); ante ellos debe oplar, "entre la opción por la 
muerte o por la vida discurre la existencia humana" (p. 109); y según esa opción se decide la propia vida del hombre, "caminar según la carne ...conduce a la muerte... caminar según el Espiritu conduce a la vida" (p. 93).

Espiritualidad es, pues, caminar pero con un contenido fundamental: propiciar la vida y asi vivir, en presencia de otra alternativa: dar muerte y así morir. Plantear asi la espiritualidad es muy importante. Negativamente, para terminar con la consciente o inconsciente comprensión de la espiritualidad como si ésta se constituyese en el ámbito de lo espiritual incorpóreo y su alternativa fuese la materialidad. La alternativa en la que se constituye la espiritualidad no es la de alma y cuerpo, espiritu y materia, sino la de vida o muerte (p. 111).

Positivamente se esclarece en lo fundamental qué significa "caminar según el Espiritu" (p. 85). Significa vivir según el "principio de dinamismo y de vida" (p. 98), que es el amor (cfr. capítulos II y III). Significa optar positivamente y en contra de su contrario, "la vida según el Espíritu (es) ...de acuerdo con la vida, el amor, la paz y la justicia - los grandes valores del Reino de Dios-y contra la muerte" (p. 111). Significa asumir el hecho central pascual de la fe cristiana, "dar testimonio de la vida, implica el paso por la muerte" (p. 73).

Este es el gran marco teológico de la espiritualidad. Dentro de él habrá que considerar muchas otras cosas, pero no a la inversa. Espiritualidad es vida cristiana en totalidad, vida en la realidad trinitaria de Dios a la manera histórica. Es éste un enfoque de la espiritualidad estricamente teologal. Lo que está en juego es una verdadera teología de la historia, de la cual la espiritualidad no es sino la repercusión en el sujeto.

1.1.2. El encuentro con el Señor en el pobre. Por lo dicho es evidente que la espiritualidad necesita historia concreta porque la historia de Dios es concreta. Por lo que toca a América Latina, se ha presupuesto ya que Dios está pasando novedosa y poderosamente por esta historia. Pero asi ha sido siempre en el surgimiento de las grandes espiritualidades. "Toda gran espiritualidad está ligada a los grandes movimientos históricos de una época" (p. 45), movimientos que en un primer momento no son o no tienen por qué ser intraeclesiales, sino históricos (p. 48).

Esto es importante recalcarlo y GG lo hace con claridad. Desde la estructura teológica de la espiritualidad se sabe que ésta debe historizarse, pero no se sabe cómo debe ser esa historización. Una vez historizada la espiritualidad ésta se podrá comparar con la estructura de toda espiritualidad; una historización adecuada además - que es lo que está ocurriendo ahora- ayudará a redescubrir las dimensiones de toda espiritualidad. Pero antes de que eso ocurra algo debe acaecer en la historia. Asi se explica que en la historia de la Iglesia haya habido y haya tenido que haber diversas espiritualidades, diversas sintesis del caminar en el Espiritu.

Lo que diferencia a esas espiritualidades no son, por lo general, sus elementos formales (encuentro con el Señor, caminar en el Espíritu, ruta hacia el Padre), 
sino "el núcleo alrededor del cual se construye un camino espiritual" (p. 135). "Una determinada espiritualidad significa siempre una reordenación de los cjes fundamentales de la vida cristiana partiendo de una intución central... Lo que establece la diferencia entre una espiritualidad y otra no está en los ejes mencionados que son normalmente los mismos, sino en el orden nuevo que se crea entre ellos, en el modo de hacer la sintesis. Y esto viene de la experiencia que da origen a un camino espiritual' (p. 135).

Esta experiencia es en América Latina el encuentro con el Señor en los pobres. GG recalca que el hecho mayor de la historia del continente es la "irrupción del pobre" (p. 12) en un continente cristiano. Esta intuición original de la TL la aquilata como veremos. Pero veamos antes lo esencial de esa irrupción como capacitante para una experiencia de totalidad.

Los pobres de América Latina son en primer lugar y estructuralmente hablando los que viven "en tierra extraña" (p. 20), frase bíblica que se les aplica en totalidad porque su extrañamiento se extiende a toda su realidad, y también de manera específica porque su pobreza proviene del extrañamiento de la tierra, que sólo pertenece a Dios, por causa de estructuras injustas (p. 23). Y esos pobres son realidades también concretas y particularizadas, lo cual recuerda GG, de manera todavía más expresiva que Puebla, al hablar del "interminable desfile de las miserias de los pobres." "Mil pequeñas cosas: carencias de todo tipo, abusos y desprecios sufridos, vidas torturadas en busca de trabajo, increibles maneras de ganarse la vida o más exactamente un pedazo de pan, rencillas mezquinas, separaciones familiares, enfermedades inexistentes ya en otros niveles sociales, desnutrición y muerte infantil, pago injusto por sus productos o mercaderias, desorientación total en cuanto a lo que es más necesario para ellos y sus familias, delincuencia por abandono o desesperación, pérdida de valores culturales propios" (pp. 17Is). Estos son los pobres reales, sujetos de una aclivo empobrecimiento y por ello "victimas" (p. 23), y de un empobrecimiento tal que "la pobreza significa muerte" (p. 21). Muerte fisica y real, en primer lugar, pero muerte más abarcadora, "muerte cultural, porque el dominador busca el aniquilamiento de todo lo que da unidad y fuerza a los desposeidos para hacerlos asi presa más fácil de la mquinaria opresiva" ( $p$. 21).

Esta pobreza sigue siendo lo más flagranle en América Latina, pero no lo más novedoso. En el continente existe también "el canto de los pobres" ( $p$. 35). La novedad consiste en una nueva conciencia, en "un pueblo que empieza a percibir las causas de esa situación de injusticia y busca sacudirse de ella" ( $p$. 37); en sus propias realizaciones de solidaridad, amor, oración, etc. (pp. 37-44), en un pueblo que posee su propio espiritu y, como su fruto más maduro y desconcertante, que posee la alegría. La alegria de los pobres, tema que GG ha analizado con agudeza, es la señal de la gran novedad. "El pueblo pobre y creyente nunca ha perdido su aptitud de festejar, de celebrar a pesar de sus duras condiciones de vida" (p. 173). Pero ahora su alegría es más consciente porque ha pasado la prueba; es alegria en medio del sufrimiento, la pobreza y la represión consciente. Si se mantiene la alegría es que hay una gran esperanza (p. 172) y ésta es más fuerte que la pobreza y el sufrimiento. "Lo que se 
opone a la alegría ...es la tristeza, no el sufrimiento" (p. 172). Este abunda, pero aquélla no se ha apoderado de los pobres. Por eso este pueblo puede cantar y en ello muestra que tiene su propio espíritu.

La irrupción del pobre en la manera descrita no es un hecho más, sino lo que descubre la verdad de toda la historia desde su reverso, lo que muestra el necesario hacia-dónde de esa historia y la necesidad de una praxis transformadora. En el pobre aparece el universal concreto con fuerza para que aparezca la totalidad o, al menos, con más fuerza que la que poseen otros universales concretos.

Por esa razón la irrupción del pobre puede ocasionar una experiencia espiritual tolalizante. Sería un error considerar la pobreza sólo como dalo fáctico material, socio-económico, con capacidad quizá de poner en movimiento las capacidades analiticas, éticas o práxicas del sujeto. La irrupción del pobre puede poner en movimiento a todo el sujeto, le atañe en totalidad; exige y permite que se responda con totalidad y por ello permite y exige una experiencia espiritual. Hay que estar claro que lo que se llama material en la pobreza es algo más que material; es la vida y la vida del otro lo que está en juego. Por tener que ver con la vida y con la vida del otro se puede tener una experiencia espiritual del pobre. "No es mi cuerpo, sino el cuerpo del pobre -el cuerpo débil y desfalleciente del pobre - el que hace entrar lo material dentro de una perspectiva espiritual" (p. 154s). Por otra parte, porque el pobre irrumpe con su propio espiritu es no sólo cuestionamienlo, sino invitación. La irrupción del pobre exige una respuesta liberadora, pero es también don y gracia para mantener la esperanza, para proclamar un sentido para la historia, absolutamente cuestionable para quien la ve desde la pobreza que genera, pero esperanza mantenida por aquellos que menos debieran tenerla. Y de esa irrupción del pobre se dice que es mediación del encuentro con el Señor.

Bien sea, pues, que la realidad latinoamericana sea vista desde Dios y su voluntad, bien sea que sea vista desde la irrupción del pobre, aparece como lo que atante en cotalidad al espíritu del hombre, como lo que exige un poderoso acto de su espiritu y como lo que lo posibilita. El seguimiento de Jesús cobra hoy sus características concretas descle la irrupción del pobre, exige caminar con ellos y ser para ellos. Por su parte, la irrupción del pobre vuelve a iluminar la realidad de Dios, como Dios de la vida, y el caminar en el Espiritu como el propiciar la vida.

\subsection{La experiencia de Dios}

En el origen de toda espiritualidad hay siempre una experiencia espirilual (pp. 14,16,59,61,83) que es descrita como "un encuentro con el Señor y su voluntad" (p. 61). En esa experiencia se encuentra la voluntad de Dios, que consiste en hacer su reino, y se encuentra al Dios que quiere un reino; el hombre es cuestionado en ese encuentro en lo que debe hacer y en lo que él es. GG. asienta cuál es la voluntad de Dios: "Dios quiere la vida de aquélios que ama" ( $p$. 49), con la conclusion: "Liberar es, en definitiva, dar vida. Toda la vida" (p. 14). Pero recalca que el mismo Dios se ha hecho presente. "La irrupción del pobre en la sociedad e Iglesia latinoamericana es, en última instancia, una 
irrupción de Dios en nuestras vidas" (p. 49). Veamos el análisis de la experiencia del encuentro con Dios mismo.

En el origen de la experiencia espiritual existe un encuentro con Dios que GG describe en la más profunda tradición biblica como algo personal, gratuito y exigente. "Encontrar al Seffor es antes que nada ser encontrado por El ...En ese encuentro descubrimos dónde vive el Seffor y cuál es la misión que nos confia" (p. 63). Ser encontrados por el Sertor es la experiencia del amor de Dios, más aún, la experiencia de que el amor es la realidad que nos descubre lo que somos y nos capacita para serlo. El que Dios haya salido a nuestro encuentro, simplemente porque nos ama, es lo que hace que nos encontremos con él y como él es, y es lo que hace que podamos definirnos a nosotros mismos como quienes somos para salir al encuentro de los otros. "La gratuidad marca nuestras vidas de modo que somos llevados a amar y a buscar ser amados gratuitamente" (p. 165).

Esa experiencia de ser encontrados por Dios es insustituible y tiene carácter fundamental y fundante. No es algo que acaece sólo en los inicios de la espiritualidad, sino algo a lo que hay que regresar, como el apostol Juan recordaba su encuentro con Jesús - "eran las cuatro de la tarde"-, como las comunidades cristianas recordaban su primera comunidad (cfr. Hech 2,41-47), como San lgnacio de Loyola recordaba a Manresa como a "su Iglesia primitiva" (p. 83). A ello hay que volver porque de ello se vive; esa experiencia proporciona la dirección fundamental al proceso espiritual y "es fuente de una gran libertad" (p. 83). La experiencia de Dios es, pues, fundamental y de ella depende la profundidad de la liberacion emprendida.

Lo que GG aftade vigorosamente en este libro es que de esa experiencia de Dios depende también la posibilidad de encontrar realmente al pobre, de dejar que el pobre irrumpa realmente en nuestras vidas. Ya se ha mencionado antes la unidad diferenciada de experiencia de Dios y experiencia del pobre, de modo que ambas se refuerzan dialécticamente. GG profundiza ahora en uno de los polos de la dialectica y expresa su absoluta necesidad; sin verdadero encuentro con Dios no hay verdadero encuentro con el pobre. $\mathrm{Y}$ es importante recordar que la necesidad de profundizar en la experiencia del encuentro con Dios proviene de la misma realidad de los procesos de liberación, lo cual, además, es garantía de su dirección cristiana porque retorna a y profundiza en sus origenes. Con toda claridad lo dice GG:

Se comprendió a partir de ese texto (Mt 25,31-46) que el encuentro con el pobre a traves de obras concretas es paso obligado para cl encuentro con Cristo mismo. Pero se fue entendiendo igualmente que el encuentro verdadero y pleno con el hermano requiere pasar por la experiencia de la gratuidad del amor de Dios. Se llega asi al otro, liberado de toda tendencia a imponerle una voluntad ajena a él y desprendido de uno mismo, respetuoso de su propia personalidad, de su necesidad, de sus aspiraciones. Si el projimo es camino para llegar a Dios, la relación con Dios es la condición del encuentro, de verdadera comunión con el otro... La experiencia de la gratuidad del amor de Dios - dato primero de la fe cristiana- no só- 
lo no se sitúa como en un paréntesis histórico, sino que da al devenir humano - y desde dentro- su total significación (p. 169).

Lo mismo repite desde la observación histórica. "La práctica de estos años ha mostrado que el acercamiento al mundo del pobre debe ser hecho sin triunfalismo de ninguna clase" (p. 189), sino más bien "demanda una gran dosis de humildad" (p. 189). Esto es lo que en lenguaje evangélico se denomina "infancia espiritual" definida como la "actitud de apertura a Dios, la disponibilidad de quien todo lo espera del Señor" (p. 189). Y GG antade con claridad:

Tal vez anteriormente fuimos más sensibles a la relación que anotábamos páginas más arriba: sólo se vive el despego a los bienes de este mundo (lo que representa un aspecto de la pobreza espiritual) en la inserción en medio de la pobreza. Percepción que sigue siendo válida, por cierto; pero a ella se añade otra más honda aún: sólo desde la infancia espiritual es posible comprometerse verdaderamente con los pobres y oprimidos de nuestro subcontinente (p. 190).

Estas palabras son notables, pudieran parecer incluso desconcertantes proviniendo de la TL; pero son evangélicas y responden a la propia experiencia desde dentro de los procesos de liberación. Con ellas no se niega en absoluto la importancia decisiva del encuentro con el pobre ni la exigencia de liberación; todo lo contrario. Tampoco se cae con ellas en un dualismo de Dios y pobres, trascendencia e historia, recibir el don de Dios y realizar sus exigencias. Tampoco se propone estrictamente hablando una cronología de la experiencia espiritual, como si lo primero fuera asegurar la experiencia de Dios con mecanismos absolutamente autónomos y, una vez realizada, acercarse al pobre. Lo que hay aqui es una reorganización lógica de los elementos de esa experiencia. Precisamente porque por la propia naturaleza de la liberación hay que ir en verdad al pobre y liberarlo en verdad de su pobreza, hay que asegurarse de que es el pobre al que se ha encontrado y es su liberacion lo que se pretende. Para ello se ofrece la lógica de la revelación de Dios. Para realizar el amor a los hermanos hay que tener experiencia del Dios que nos ha amado primero. En la experiencia del ser amados por Dios se sabe lo que es el amor a los hermanos, aunque históricamente tenga que haber también experiencia del amor humano para poder hablar con sentido del amor de Dios. Lo que sencillamente quiere decir GG es que 'todo comenzb con Dios' y que eso tan absolutamente simple debe ser mantenido para que todo prosiga según Dios. Quien realmente se sabe amado por Dios mejor amará al hermano, quien ha sido purificado en su mirada por Dios con más limpieza verá el mundo del pobre, quien más ha experimentado la misericordia y el perdón de Dios más misericordioso y comprensivo será con el pobre, quien ha captado que Dios es amor y puramente amor con mayor desinterés y eficacia buscará la liberación del pobre.

La experiencia de Dios ni presupone ni propicia el salirse de la historia, sino que exige y anima a introducirse más y mejor en ella, pero según Dios. De lo que se trata es de hacer realmente la experiencia de Dios, que no debe confundirse con sus mecanismos convencionales, aunque pueda expresarse en ellos, y que se verifica cuando el hombre se parece más a Dios. Esa experiencia 
de Dios ocurre cuando ocurre; pero cuando el hombre se ha encontrado con Dios, ha sabido que Dios lc ha salido al encuentro y le ha remitido de nuevo a la historia, entonces todos los elementos de su experiencia se organizan de una manera precisa que puede describirse asi:

La alegria provocada por la presencia del amor de Dios ensancha el corazón para la acción de gracias y para la acogida a los clemás. Por ello en ese cántico (el Magnificat) se entrelazan la confianza y la entrega a Dios con la voluntad de compromiso y cercunia a sus predilectos: los humildes y hambrientos (p. 191).

\subsection{Incorporarse a la espiritualidad del pueblo}

En el apartado anterior se ha mencionado la dimensión personal, de encuentro y experiencia de Dios, de la espiritualidad. Pero esto no significa ni espiritualidad individualista ni elitista, a las que se analiza y cuestiona (pp. 2532). La espiritualidad debe ser más bien popular en un sentido bien preciso. Indudablemente tanto en materia de espiritualidad como en otras muchas hay $\mathrm{fi}_{\mathrm{i}}$ guras señeras que en un determinado momento expresan una determinada espiritualidad, y la historia de la espiritualidad suele reducirse normalmente a su estudio. Pero tanto en el AT como en el NT como en la realidad latinoamericana los pueblos y las comunidades son los primeros sujetos de espiritualidad. Esto es lo que se indica en el subtítulo del libro: "En el itinerario espiritual de un pueblo."

En el libro se recuerda la ejemplaridad del éxodo y de la comunidad primitiva cristiana para la espiritualidad. Lo que da sentido en el éxodo a la obra de Dios y a la obra protagonizada por Moisés es la liberación de todo un pueblo y la alianza con todo un pueblo. "Salir de Egipto es romper con la muerte (eso es lo que esclavitud y carencia significan) para ir al encuentro con Yahvé y convertirse en su pueblo" (p. 114).

Ese protagonismo histórico y teológico del pueblo, que debiera ser evidente a priori desde la revelación, es lo que está recobrándose en América Latina. "Hay una historia que ha comenzado a ser forjada por los pobres y desposeidos, los privilegiados del Reino" (p. 20). Y esa historia es la que exige y está propiciando una nueva espiritualidad que tiene como sujeto al pueblo.

Las luchas del pueblo pobre por la liberación representan una afirmación de su derecho a la vida; puesto que la pobreza que sufre el pobre significa muerte, muerte prematura e injusta. Desde esta afirmación de la vida, los pobres del subcontinente intentan vivir su fe, reconocer el amor de Dios y proclamar su esperanza. En el seno de esas luchas, llenas de avatares, el pueblo oprimido y creyente se hace cada vez más agente de una manera de ser cristiano, de una espiritualidad. Dejará de ser consumidor de espiritualidades, valiosas sin duda pero que corresponden a otras experiencias y a otras metas, porque va forjando un camino propio para ser fiel al Señor y fiel a las vivencias de los más pobres (p. 48).

Esto es algo nuevo y la superación del elitismo en materia de espiritualidad, "que el sujeto de la experiencia que abre la ruta a una espiritualidad es un 
pueblo entero y no una persona aislada" (p. 50). Sin duda existen personas que expresan con más brillantez y claridad la espiritualidad, pero ésta no es en último término su propia creación, sino expresión y sintesis más acabada de lo que existe en la realidad de los pueblos y de las comunidades. De ahí se sigue una consecuencia que GG expresa con vigor:

Para muchos cristianos en América Latina actualmente la posibilidad del seguimiento de Jesús se juega en su capacidad para incorporarse a la experiencia espiritual del pueblo pobre. Esto les exige una conversión profunda: se trata de hacer suya la experiencia que los pobres tienen de Dios y de su voluntad de vida para todo ser humano (...)

Esa nueva realidad invita a salir de un mundo familiar y frecuentado, y lleva a muchos a releer la propia tradición espiritual. Se trata sobre todo de hacer nuestro el mundo del pobre, su manera de vivir la relación con el Señor y de asumir la práctica histórica de Jesús. De otro modo se discurrirá por una senda paralela a la emprendida por el pueblo oprimido y creyente. Se intentará entonces establecer algunos puentes para ligar esas rutas diferentes: compromiso con los explotados, relaciones de amistad con algunos de ellos, celebrar la eucaristía con las comunidades populares, etc. Esfuerzos meritorios sin duda, pero insulicientes porque esos vínculos no eliminan el paralelismo mencionado. Ahora bien, la experiencia espiritual que vive el pueblo pobre es demasiado profunda y englobante para merecer sólo ese tipo de atención. Por ello hablamos de incorporarse a dicha vivencia. Ese es el asunto. Todo lo demás es quedarse a mitad de camino (p. 51).

Este párrafo es importante. Teóricamente no deberá causar sorpresa pues en la revelación de Dios su correlato es, ante todo, un pueblo, al cual desea liberar y con el cual desea establecer una alianza, "Yo seré tu Dios y tú serás mi pueblo;" de la Iglesia se dice que es ante todo "pueblo de Dios;" sobre la fe se dice que "la universalidad de los fieles no puede fallar en su creencia" (LG n. 12); de la propia liberación se dice que los mismos pobres deben ser sus agentes primarios. El 'pueblo,' en cuanto comunidad dentro de la cual vive, cree y realiza su vida cristiana la persona individual, es una dimensión esencial en la comunicación de Dios a los hombres y en la respuesta de los hombres a Dios. Esto no hace desaparecer lo personal-individual ni en el ser amados y exigidos por Dios ni en su respuesta a Dios, pues cada hombre tiene un rostro concreto ante Dios y la aceptación y la respuesta de la fe no pueden ser delegadas en otros. Pero todo ello acaece dentro de un pueblo y de tal manera que -cristianamente- la apertura al pueblo, la disponibilidad a dar y recibir de él y dentro de él, es esencial a la constitución del creyente también en cuanto creyente personal-individual.

Esto debe extenderse también a la espiritualidad. No se trata de exigir imposibilidades psicológicas o sociológicas para aquellos que no son históricamente pueblo pobre; quienes deben afrontar crisis desconocidas para el pueblo, la de la Ilustracion por ejemplo, y quienes tienen responsabilidades especílicas por el determinado lugar que tengan dentro de la sociedad y de la Iglesia. De lo que se trata es de tomar en serio la intuición original de una Igle- 
sia de los pobres: que el pueblo pobre es su centro de inspiracion en lo doctrinal, teologico, práxico y -ahora- también en la espiritualidad. Se trata de que la espiritualidad del pueblo pobre, lo lundamental de su fe y de su esperanza, sus valores espirituales concretos, su generosa entrega por amor, configuren la espiritualidad de todos y le den su dirección concreta, aunque en el modo de realizarla nadie pueda prescindir de otros condicionamientos y otras posibilitaciones.

Parafraseando las conocidas palabras de Mons. Romero dice GG: "A esto hemos sido llamados, a resucitar con el pueblo en materia de espiritualidad" (p. 53). En esto está en juego la tesis fundamental del libro tal como aparece en su título: "La fe y la esperanza en el Dios de la vida que anida en la situación de muerte y de lucha por la vida que viven los pobres y oprimidos en América Latina: ése es el pozo en que tenemos que beber si buscamos ser fieles a Jesús"' (p. 54).

\subsection{La espirilualldad de la liberaclón y sus rasgos concretos}

Hasta ahora se ha analizado la estructura fundamental de la espiritualidad y sus dos condiciones principales, que sea teologal y que sea popular. Queda por describir sus contenidos concretos, es decir, no ya qué sea espiritualidad, sino quién es el hombre espiritual, el pueblo espiritual, atendiendo tanto a lo que dice la revelación como a la realidad histórica.

Elegir una formulación sintética de esa realidad no es fácil por la diversidad de elementos que comporta la espiritualidad y porque una vez formulada puede ser discutible tebricamente en cuanto formulación sintética. GG se decide por la siguiente formulacion: "Libres para amar" (p. 137), pues "toda espiritualidad es un camino of recido para el mejor servicio de Dios y de los demás: libertad para amar" (p. 135). Desde el principio hay que notar la raigambre neotestamentaria de esta formulación, pues en el NT espiritu y libertad se dan la mano. Lo que enseguida hay que añadir es que la libertad del hombre espiritual debe ser entendida bíblica y no liberalmente. El hombre libre es el hombre liberado de si mismo, pero no para si mismo, sino para el otro. El 'para' que une a la libertad y al amor pudiera interpretarse equivocadamente como si se pudiera ser libre 'para' varias cosas. Neotestamentariamente el 'para' de la libertad solo puede relacionarse con el amor a los demás, a través de lo cual el hombre se recobrará a si mismo y será también para si mismo, pero no en directo, sino a traves del rodeo del para-los-demás. Eso es lo que gráficamente expresa GG al elegir dos citas neotestamentarias para ilustrar la libertad para amar. "Siendo yo libre de todo, a todos me esclavicé" (1 Cor 9,19) afirma Pablo; "Nadie me quita la vida, soy yo quien la entrega" (Jn 10,18) (p. 140) afirma Jesús en el evangelio de Juan. Libertad del sujeto y sujeto que se entrega por amor son correlativos; ese sujeto libre es el hombre espiritual.

Esta sintesis del hombre espiritual es lo que GG ve que es realidad en América Latina, con mayor o menor perfección y definitividad, pero con suficiente realidad como para poder hablar de una espiritualidad realizada. "La verdad es que el contacto cotidiano con las vivencias de algunos, la lectura de textos de muchos, asi como el testimonio de olros, nos convencen de la hondu- 
ra de la experiencia espiritual que se vive en el presente entre nosotros" ( $p$. 143).

Se trata entonces de describir qué son esos hombres y mujeres espirituales. Para ello GG analiza cinco rasgos concretos de espiritualidad que describen la libertad para amar. "Conversión: exigencia de solidaridad" (p. 144); "Gratuidad: clima de eficacia" (p. 161); "Alegria: victoria sobre el sufrimiento" (p. 171); "Infancia espiritual: condición del compromiso con los pobres" (p. 183) y "Comunidad: desde la soledad" (p. 191). Los titulos y la dialéctica interna que reflejan están cuidadosamente elegidos. Se trata con ello de dar cuenta de los rasgos fundamentales de la espiritualidad de manera que, en su conjunto, describan su totalidad; pero se trata también de mostrar la conciencia que se tiene de esa totalidad, no sólo por acumulación de rasgos, sino manteniendo la dificil dialéctica entre todos ellos y dentro de cada uno de ellos. "Importa no aislar los elementos, porque sólo así se puede percibir lo que tienen de propio esos rasgos" (p. 143).

La lectura de esta parte del libro (pp. 137-202) no puede ser sustituida por el análisis, pues por definición se narra aqui la realidad del hombre y del pueblo espiriıual. Nos reduciremos a algunas reflexiones que puedan acompañar esa lectura.

En la selección y formulación de los rasgos del hombre espiritual GG insiste en qué consiste la síntesis y cómo se realiza. Hay rasgos que apuntan más bien a lo que es el hombre espiritual en cuanto liberado de sí mismo (conversion, gratuidad, alegria, infancia espiritual, soledad ante Dios) y hay rasgos que apuntan más bien al hombre espiritual en cuanto liberador (solidaridad, eficacia, sufrimiento, compromiso, comunidad) aun cuando no sea tan simple adjudicar los diversos rasgos a los dos aspectos del hombre espiritual. Pero lo fundamental que se quiere decir es que la verificación histórica de que existe un hombre liberado es si produce frutos para la liberación y que éstos serán más profundos y duraderos en la medida en que provengan de un hombre liberado de sí mismo.

Aunque de todos o casi todos estos rasgos se haya escrito ya en TL existe una relativa novedad en el tratamiento y énfasis que se pone en la necesidad de la propia liberación para la liberación del otro. La insistencia no sólo en la primera conversión, sino en la necesidad de un proceso de conversión dentro de la liberacion, de la infancia espiritual, de mantener la alegría y la soledad ante Dios etc., son realidades a tener en cuenta explicitamente, a cultivarlas, a no ignorarlas, ni pensar que se puedên deducir quasi mecánicamente de la acción liberadora.

La realidad y necesidad de estos rasgos del hombre liberado se han ido redescubriendo y realizando dentro del mismo proceso de liberación y se han vuelto a releer en los origenes de la fe y en la tradición espiritual de la Iglesia. Con ello hay un reconocimiento in actu no sólo de la necesidad formal de volver a las fuentes, sino de su verdad y eficacia. Se reconoce la sabiduria cristiana fundante en la revelación de Dios y la sabiduría acumulada a lo largo de la historia de que el hombre, aunque remitido necesariamente a una historia 
concreta, necesita en cualquier concreción la liberación de sí mismo. Se reconoce que el Espiritu de Dios actúa en dar vida y en introducir en la verdad tal como va apareciendo en la historia, pero también en liberar al hombre de sí mismo, en sacarlo de sí mismo. Se reconoce la necesidad de la purificación del hombre de si mismo. Y, por ello, se aducen ejemplos de otras épocas de la historia, los cuales se siguen considerando importantes a pesar de que su praxis del amor sea distinta a la actual. Si se toman en serio las referencias que hace GG a San Francisco de Asís, San Juan de la Cruz, Santa Teresa, San Ignacio, etc., se comprende la decisiva imporlancia que otorga a que el hombre se libere de si mismo para ser el hombre espiritual.

Pero el ideal del hombre liberado es exigido en el fondo para que sea mejor liberador, que sea libre para amar. Con ello se mantiene y se potencia la intuición original de la TL. La nueva espiritualidad nace "en el contexto de la lucha por la liberación en vista al amor y la justicia" (p.141). Y este contexto historiza novedosamente los rasgos perennes de la liberación de uno mismo. La conversión debe realizarse ante el propio pecado y ante el pecado del mundo (p. 147) con la crudeza con que se le ha descrito antes, un pecado que da muerte. Ante ese pecado hay que examinarse personalmente, por la connivencia con él o por las omisiones que lo dejan intacto (p. 146s). La experiencia espiritual de la conversión se realiza también entonces en presencia de la miseria de los pobres, del pecado del mundo. "Tal vez por mucho tiempo esta perspectiva no estuvo presente en el tratamiento del tema en la literatura espiritual; hoy no es posible, sin embargo, dejarla de lado. El encuentro con el Señor en lo más hondo de cada uno no excluye, exige más bien, saber encontrarlo en el fondo de la miseria en que se halla el pueblo pobre de nuestros paises" ( $p$. 149). Conversión supone pecado y pecadu supone ofensa a Dios y ofensa al pueblo pobre; conversión es entonces volver a Dios y volver al pueblo pobre; y esto último exige "una conversión más radical para entrar en otro universo, el mundo del pobre" (p. 149).

El volverse al pueblo pobre es solidaridad con ellos y amor a ellos. GG insiste de nuevo en que se trata de verdadero amor a seres humanos concretos: "sin amistad, cariño, sin ternura - ¿por qué no decirlo? - no hay verdadero gesto solidario" (p. 157). Pero insiste en que ese amor debe ser proporcionado a la opresión de que se quiere liberar; debe ser amor social y eficaz, pues aunque existen los pobres tomados individualmente, existe todo un mundo de pobres, mayoritario y aterrador. "Amar a alguien implica amarlo igualmente con su textura social" (p. 152). De ahi que la solidaridad y el amor tengan que analizar las causas de la pobreza y de la muerte, "descubrir los mecanismos sociales que hacen del obrero y del campesino personas marginadas" (p. 148), como dice citando a Mons. Romero. Y todo ello porque el amor desea ser eficaz. Aquí GG ofrece una fina fenomenologia del amor y desenmascara los peligros e insuficiencias del amor presentes en las espiritualidades. Para el amor no basta con la intención amorosa que no analiza los resultados objetivos del amor (p. 161), ni basta con una realización del amor llevada a cabo para cumplir con el "deber" a priori de amar (p. 162). El amor tiene más bien que responder a las necesidades objetivas de los pobres y desvivirse por solu- 
cionarlas. "La preocupación por la eficacia es una manera de expresar el amor por el otro" (p. 162). En este contexto hay que entender lo dicho antes sobre la gratuidad como característica del hombre espiritual. Con ella y en ella hay que vivir porque asi es la comunicación de Dios con el hombre y asi debe realizarse nuestro propio amor a los otros. Pero ese clima de gratuidad nada quita de urgencia a la eficacia del amor. "La gratuidad del don del Reino no la suprime, la exige más bien" (p. 162).

GG enfatiza la necesidad de soledad interior, tema biblico por excelencia en lo que tiene de positivo -el desierto como el lugar de la experiencia de Dios- y en lo que tiene de trágico como la soledad de Jesús en el huerto y en la cruz o en las lamentaciones de Jeremías; tema clásico también de la espiritualidad de los místicos, tema del existencialismo y de la teodicca. GG no disimula su necesidad para la constitución del hombre espiritual liberado; pero, de nuevo, la historiza desde la liberación. "Esta experiencia de soledad adquiere rasgos propios en nuestra situación" (p. 192). "El paso por la vivencia dolorosa y honda de la soledad" (p. 191) que le compete a todo ser humano y a todo cristiano es, en primer lugar, "el paso por lo que se ha llamado "la noche oscura de la injusticia"" (p. 192). Esta produce soledades menores aunque dolorosas en quienes practican la liberación: amenazas, ataques de los poderosos cuestionados, aislamiento por fidelidad a un nuevo camino de solidaridad con los pobres, desconfianzas dentro de la misma Iglesia (p. 193). Pero no son la soledad mayor. Esta es la sensación de impotencia ante "la situación de pobreza y explotación de los pobres" (p. 193), la interminabilidad de sus sufrimientos, lo oscuro del túnel, el elevadisimo costo humano de sus luchas, etc. Esa soledad ante la historia y ante Dios es la que haría razonable la pregunta por la teodicea; pero por ella hay que pasar. Hay que mantener el grito de Jesús: "Dios mio, Dios mio, ¿por qué me has abandonado?" cuando "solamente queda la convicción de hacer la voluntad del Padre y de servir al pueblo pobre" (p. 194).

Soledad aqui no significa individualidad ni menos aún volverse a uno mismo, buscar refugio en uno mismo, preocupación narcisista por uno mismo. Es más bien honradez ante y dentro de la historia de la injusticia y honrada pregunta a Dios. GG no escamotea este aspecto del hombre ni con fáciles doctrinas ni con esperanzas baratas; exige más bien que sea asumido y afirma que sólo asi se constituye el hombre espiritual. Lo que añade es que esa soledad, y debido a esas causas, es lugar de oración y condición de verdadera comunidad. "La confianza en Dios y en la comunidad eclesial se presenta entonces, aunque la luz todavía no aparezca" (p. 195). Quien es capaz de vivir esa soledad, quien es purificado por ella, recibe el don de la confianza y de la comunidad. Bellamente dice GG: "El paso por la experiencia de soledad lleva a un hondo vivir en comunidad. Efectivamente, lo hemos notado ya, la soledad de que hablamos es algo muy distinto al individualismo. Este tiene mucho de repliegue intencional e interesado para mantenerse en las aguas tranquilas de la privacidad. A ella vendrán otros, quizás, a tocar a la puerta y se les abrirá como quien hace un favor. Se afiade entonces, graciosamente, una vertiente comunitaria a una existencia cristiana ya autosuficiente" (p. 196). 
Realidad novedosa y masiva, cruel y esperanzadora, es la persecucion y el martirio en América Latina. "En toda espiritualidad hay siempre una dimensión martirial" (p. 174) y la hay también en la latinoamericana. Pero, de nuevo, no sólo porque lo martirial en cuanto testimonio y en cuanto seguimiento de un Señor crucificado deben seguir siendo exigidos a priori, sino por la realidad concreta de América Latina. "Defender hoy el derecho de los pobres a la vida, en América Latina, lleva Cácilmente al sufrimiento e incluso a la muerte" (p. 173).

El hecho como tal es evidente, aunque su interpretación debe ser cuidadosa. Por una parte no se debe glorificar el hecho hasta tal punto que haga ignorar el gravísimo pecado que expresa y supone. El martirio cristiano expresa una muerte mucho más generalizada, estructural y lenta, pero real, de pueblos enteros crucificados y de muerte violenta de quienes defienden el derecho de los pobres. No se puede, pues, olvidar "la crueldad que rodea ese hecho, y por lo tanto el rechazo que deben producir las condiciones que dan lugar a esos asesinatos" (p. 175). Algunos temen incluso que el énfasis en lo martirial introduce un dolorismo en la fe cristiana que le es contrario a su último fundamento y su última meta: la resurrección.

Pero el martirio sigue siendo una realidad cuyo hecho no se puede negar así como la exigencia en principio de dar la propia vida para la vida de los pobres. Y cuando de hecho ocurre, entonces aparecen también los hombres espirituales, los libres para amar, los que "dan su vida por su fe en el Dios de la vida y su amor por los despojados" (p. 174). Entonces ocurte también algo improgramable que es mucho más que un producto del movimiento compensatorio o hacer de la necesidad virtud. Surge la alegría pascual (p. 177) y la esperanza que se apoya "en el testimonio de los que han sabido entregar sus vidas" (p. 159). Ni la alegría es gozo inconsciente ni la esperanza es optimismo barato. Ambas se producen porque los mártires crean el verdadero clima del amor, ejemplificado en ellos mismos e imbuido en otros por ellos. Y en ese clima surge la convicción profunda de que la muerte no tiene la última palabra, aunque para que surja la vida haya que pasar por aquella. De la manera escandalosa que aparece en el siervo de Jahve, en Jesús crucificado y en las primeras comunidades cristianas, cuyo destino es la persecución, surge una y otra vez la pascua y la experiencia pascual: "voluntad de vida para todos desde la alegria, despues de la experiencia del dolor y la muerte" (p. 181).

Hombres espirituales, comunidades espirituales, pueblos espirituales, son los que están dispuestos -dicho con la mayor sencillez- a rehacer la pascua de Jesús en y por causa de la situación historica del continente y a rehacer, por ello también, la vivencia teologal de Jesús en la cruz y de los mártires, y a rehacer la vivencia de quienes se encontraron con el resucitado y le siguen encontrando en comunidades y pueblos crucificados.

Todos estos rasgos que sintetizan y desembocan en una espiritualidad pascual no son otra cosa que la santidad cristiana. Espiritualidad es en último término santidad. La fe del pueblo y la TL han revalorizado la santidad, adjetivándola a veces - como cuando se habla de "santidad politica" - para que la 
misma terminología de santidad no induzca a reduccionismo o malas interpretaciones, pero proponiéndola como la sustancia de toda vida cristiana. Esto es lo que en último término tienen que ofrecer las comunidades y el pueblo pobre y ésa es también su arma más poderosa para convencer a otros y defenderse de ataques.

\subsection{Un modelo teórico de espiritualidad}

Toda gran espiritualidad tiende a formularse en un modelo teórico sintético que dé cuenta de los elementos disparejos y complementarios, del momento subjetivo y objetivo del hombre espiritual, de su relación con lo trascendente y con lo histórico. Esas sintesis acaecen cuando ha habido suficiente realidad de espiritualidad y suficiente reflexión para poder of recer dichas sintesis como algo dicente. Así, por mencionar algunos ejemplos importantes, se ha formulado el ora et labora de los primeros monjes, el contemplata aliis tradere y el in actione contemplativus.

GG no los analiza teóricamente en su libro ni elige uno de ellos para organizar conceptualmente la espiritualidad que propone ni ofrece su propia formulación sintética. Aparte del talante de modestia que recorre todo el libro, el autor piensa sin duda que para reformular un nuevo modelo tebrico se necesitaría más reflexión y tiempo; que por el momento más que acuñar nuevas formulaciones $-\mathbf{y}$ petrificarlas quizás - es importante mantener la espiritualidad abierta a las nuevas posibilidades y exigencias de la historia, que pudieran llevar a una nueva reformulación.

Pero aunque GG no analiza ni propone nuevas síntesis teóricas puede ser útil indagar las condiciones que pondría a tales sintesis. La primera sería dar primacia a la totalidad sobre sus partes, de modo que lo histórico (seguimiento, caminar, pueblo en búsqueda) y lo trascendente (de Jesús, en el Espíritu, hacia Dios) se remitiesen mutuamente. Quizás la realidad del "reino de Dios," frecuentemente mencionada en el libro, pudiera fungir como la totalidad en la cual se desarrolla y a la cual sirve el hombre espiritual. La segunda seria la superación, no anulación, de la division entre lo espiritual y lo material, de modo que ambas dimensiones se remitiesen mutuamente en el hombre espiritual: la tendencia a espiritualizar lo historico y a historizar lo espiritual. Asi por ejemplo la realidad histórica del pobre es algo que no sólo debe ser analizado y respondido de acuerdo a su materialidad, sino algo de lo que se debe tener una experiencia espiritual, algo que puede irrumpir en nuestras vidas y hacerse así mediación de la experiencia de Dios. Por otro lado, la experiencia espiritual del encuentro con Dios o de ser encontrados por Dios incluye por su propia dinámica, no sólo como raciocinio o conclusión heterogénea, salir al encuentro de la pobreza histórica y remediarla. La tercera sería el énfasis en lo procesual de la espiritualidad. Esto es lo que recalca GG al mencionar el 'caminar' en el Espíritu y al proponer como modelo la 'senda' espiritual de los misticos. Procesualidad significa que la espiritualidad necesita tiempo para constituirse, tiempo en que coyunturalmente puede aparecer diversos énfasis, tiempo para recogerlos y complementarlos, de modo que lo que se formule como modelo teórico de espiritualidad llegue a ser producto más que inicio. Por último, y a 
diferencia de los modelos mencionados formulados en singular, la espiritualidad debe mencionar el sujeto colectivo, cosa que de alguna forma estaría tambièn presente en los modelos anteriores, pues lo que expresaron y produjeron fueron órdenes religiosas y no sólo individuos, y sobre todo el sujeto popular como se ha indicado.

Según esto, algo se puede decir de la postura del libro de GG hacia los modelos mencionados, los cuales han analizado otros más explícilamente, ${ }^{17}$ y sobre lo que podria ser su pronto modelo. Como modelo teórico seria inadecuado presentar la totalidad de la espiritualidad por la adición del ora "et" labora, asi como la prioridad lógica concedida a la contemplación en el contemplata aliis tradere sin dialéctica. El primer modelo no recalca la unidad y el segundo no recalca la mutua referencia entre contemplación y acción.

Positivamente, para GG espiritualidad es libertad para amar; el amor, por lo tanto, es su finalidad y lo que unificaría los diversos elementos de la espiritualidad. El amor presupone, incluye y propicia la contemplación; pero en sí mismo es más una acción. En este caso el momento de la acción no está separado de ni subordinado a ni es sólo consecuencia del momento de contemplación. Desde este punto de vista GG pareceria acercarse más al modelo teórico del in actione contemplativus al que cita en la página 170. Contemplación y acción se remiten muluamente, la contemplacion es "demanda y elemento vivificador de una acción histórica" (p. 170), pero la acción es también lugar para la contemplación. El in actione contemplativus supone actuar sobre la historia con amor y encontrar a Dios en todas las cosas (p. 166).

No se trata ahora de hacer coincidir o alejar más o menos la espiritualidad descrita en el libro de los modelos tradicionales de espiritualidad. De lo que se trata es de unificar los momentos duales de toda espiritualidad de la manera más adecuada a la espiritualidad real de America Latina. En nuestra opinión el modelo de GG habría que buscarlo en la línea de lo que ha formulado de forma estrictamente teologal sobre la relación entre hombre y Dios: "A Dios se lo contempla y se lo practica;" 18 "el misterio de Dios vive en la contemplación y vive en la práctica." 19 En esta afirmación no desaparecen los momentos de contemplación y acción, ni desaparece la diferencia entre Dios y hombre; pero esas diferencias se relacionan entre si de una manera específica. Contemplación y acción no son momentos con objetos distintos, como si la contemplación se dirigiese a Dios y la acción fuese acción sobre el mundo; a uno y el mismo Dios hay que contemplar y practicar, y de ahí - desde Dios- la unificación profunda de ambos momentos. Por otra parte, también el mundo es objeto de acción y de contemplación. Contemplar a Dios es concomitantemente contemplar el mundo con los ojos de Dios, y practicar a Dios es hacer el mundo según la voluntad de Dios. Los momentos de contemplación y acción no se diversifican, por lo tanto, porque uno remita a Dios y el otro al mundo; tanto Dios como el mundo son objeto de contemplacion y acción. No se puede buscar ahi, por lo tanto, la dualidad más primigenia de la que vive la espiritualidad. Esta hay que buscarla en la relacion del hombre con Dios. En ella hay el momento de iniciativa de Dios, de gratuidad, y el momento de respuesta del hombre. El hombre espiritual se constituye cuando mantiene esas dos dimen- 
siones de gratuidad y de respuesta tanto en la contemplación como en la acción; pues tan gratuito es el ver como el hacer, los ojos nuevos como las manos nuevas, el dejarse encontrar por Dios como el dejarse enviar por Dios; y tan respuesta es el aceptar a Dios como el accionar sobre el mundo. El hombre espiritual se constituye en unidad cuando acaece con éxito la manifestación de Dios al hombre, manteniendo la dualidad de gratuidad y de respuesta. En esta dirección, creemos, iria el modelo teórico de espiritualidad de GG, dentro del cual se subsume la diferencia entre contemplación y acción, pero en una diferencia más originaria, la de gratuidad y respuesta, que permite una unidad más plena.

Este modelo de espiritualidad estrictamente teologal es lo que de forma sencilla propone GG al final del libro: "Sean perfectos como su Padre celestial es perfecto" (p. 204) o como Iraduce la Biblia española: "Sean buenos del todo, como es bueno vuestro Padre del cielo"' (Mt 5,48). El hombre espiritual es el hombre divinizado a la manera histórica. En concreto, para América Latina, el hombre espiritual es el que ve al pobre con los ojos de Dios y hace con el pobre lo que hace Dios. $\mathrm{Y}$ al ver asi al mundo y relacionarse asi con el mundo, el hombre se relaciona con Dios por afinidad. Lo que añade GG es que en el origen de todo está Dios: quien se ha dejado contemplar por Dios y quien ha dejado que Dios opere en él, puede contemplar unificadamente a Dios y al mundo y puede amar unificadamente a Dios y al mundo. Este enfoque no elimina las diferencias con que tiene que vérselas la espiritualidad: contemplación y acción, relación con Dios y relación con el mundo, pero la integra en otra más abarcadora y fundamental: recibir y dar, gratuidad y respuesta. Esta diferenciación y su unificación no es especulativamente recuperable porque expresa el designio misterioso de Dios: él ha decidido amar a los hombres y con la radicalidad con que aparece en Cristo. De ahí que, visto desde el hombre, lo más importante que tiene que integrar es su condición de agraciado y agraciante, todo ello a través de sus dimensiones contemplativa y práxica. En el fondo todo el libro de GG no dice más que muchos cristianos en América Latina han sido agraciados por Dios y que se han convertido en gracia para otros.

\section{Espiritualidad y teologia}

El libro de GG es un libro sobre espiritualidad y que trata teológicamente sobre espiritualidad. Con ello se constata la importancia de la teologia para la espiritualidad; el análisis teológico es útil e importante para esclarecer lo que es la espiritualidad. Pero en el libro se afirma también la proposición inversa: la importancia de la espiritualidad para la teologia, para su constitución y su relevancia. "El nivel de la vivencia de la fe sostiene el de la inteligencia de la fe ...La firmeza y el aliento de una reflexión teológica está precisamente en la experiencia espiritual que la respalda... Una rellexion que no ayude a vivir según el Espiritu no es una teologia cristiana. En definitiva toda auténtica teologia es una teología espiritual. Esto no enerva su carácter riguroso y científico. Lo sitúa" (p. 60s). Y refiriéndose más en concreto a la TL afirma: "El hablar sobre Dios (teo-logia) viene después del silencio de la oración y del compromiso... Nuestra metodologia es, a decir verdad, nuestra espiritualidad" (p. 203s). 
Que la TL es una teologia espiritual es una intuicion que se ha abierto paso en nuestros días. Asi lo reconocen muchos desde fuera y asi lo reconocen los propios teólogos de la liberación. L. Bofr afirma que "lo que sustenta la práctica y la teoria (teologia) liberadoras es una experiencia espiritual." 20 P. Richard afirma que "nuestra teología es fundamentalmente una teologia espiritual." 21 Estas afirmaciones son conocidas, pero exigentes; ponen serias condiciones a la teología y al quehacer teológico. Exigen una experiencia espiritual previa a la teología como acto segundo; pero exigen que la misma teologia sea hecha con espiritu y que comunique espiritu, que sea loda ella espiritual.

Qué significa una teologia toda ella espiritual, es decir, que no sólo presupone una experiencia espiritual ni que sólo trate temas convencionalmente espirituales es lo que queremos aclarar a continuación. En nuestra opinión esto supone que 1) se haga con y comunique espiritu en todas sus dimensiones y contenidos y 2) que en su totalidad ilumine, unilique y anime a la constitución del hombre y del pueblo espiritual.

Lo primero quiere decir que el mismo quehacer teológico y sus contenidos sean elaborados con espiritu y con el espiritu adecuado a ese quehacer y a esos contenidos. Al nivel formal, la teologia en cuanto logos debe ser esclarecedora de la verdad, debe usar un logos historico, hermenéutico y especulativo, y debe hacer uso del instrumental bíblico, filosófico, histórico, etc. Pero ese logos es verdaderamente espiritual cuando en verdad ilumina; pues no es lo mismo tratar las cosas soblo científica y doctrinalmente que iluminarlas realmente, no es lo mismo hablar sobre muchas cosas que dejarlas hablar. Cuando ocurre esto último, entonces la teologia en cuanto logos está hecha con un espíritu adecuado y comunica luz; sus contenidos no sólo son registrados en el conocimiento de su destinatario, sino que son integrados por él en su espíritu. Al nivel de contenidos, por poner algunos ejemplos, la teología trata sobre la esperanza, la práctica de la justicia, la gratuidad, etc. Pero no es lo mismo reducirse a agrupar, ordenar y explicar conceptualmente los contenidos de la fe que versan sobre la esperanza, la justicia y la gratuidad que presentarlas de tal manera que ya inicialmente muevan y animen a la práctica, generen esperanzas y comuniquen gratuidad. Cuando esto último ocurre la teología se ha hecho con espiritu y ha comunicado espiritu.

Una teologia espiritual no significa por lo tanto ignorar las exigencias de su propio quehacer ni suplirlas voluntaristamente con un lenguaje espiritualista o emocional. No se trata de eso. Se trata de que el quehacer y sus contenidos estén imbuidos del espíritu que les es propio. Que esto ocurra, en el fondo sólo se puede verificar a posteriori. Pero es importante recordar la exigencia. No cabe duda de que muchas teologias actuales desearian honradamente iluminar los contenidos de la fe para el mundo actual; pero unas logran iluminarlos de verdad y otras no, aunque escriban largos tratados sobre ellos. Muchas teologias desean enfatizar la esperanza, la práctica de la justicia, la gratuidad; pero unas generan esas realidades y otras no, aunque hablen larga y extensamente de ellas. De lo que se trata en una teología espiritual es, por lo tanto, de que se realice la tautología primigenia de que la teología sea palabra dicente; es decir, que la palabra posea su propio espíritu. 
Lo segundo quiere decir que una teología toda ella espiritual debe propiciar ánimo para la vida cristiana, dar vida -como se le atribuye al Espiritu-y unificar todas sus dimensiones y contenidos. Para ello debe remitirse a una experiencia espiritual originante - como la que describe GG, por ejemplo-, mantenerla y abrirla siempre a la historia. Esa experiencia exige a priori y ciertamente a posteriori en el mundo de hoy, en América Latina y en el primer mundo, que la teologia sea toda ella, en la elaboración de todos sus contenidos y en su propio quehacer, una teologia teologal, popular y creatural.

\subsection{Una teología teologal}

Esta tautologia nos parece importante recordarla y recalcarla sobre todo en la actualidad. Se trata, dicho gráficamente, de que la teología sepa qué hacer con Dios. Para ello no basta que la teologia hable acerca de Dios, sino que tiene que dejar hablar a Dios, a mover a que el hombre hable con Dios y remitir al hombre a Dios; en una palabra, que Dios sea una realidad para la teologia y una realidad en acción.

Esto significa, en primer lugar, que la doctrina teológica sobre Dios y la doctrina sobre cualquier contenido teológico ayude realmente a hacer la experiencia de Dios. En este sentido una teología teologal debe ser mistagogia, introducción en la realidad de Dios como él es, misterio transcendente inmanipulable y Padre cercano bondadoso y salvador. La doctrina sobre Dios debe ser de tal manera que respete su misterio e introduzca en $k$ 'l; que deje a Dios ser Dios; que integre la cuota de no saber para saber realmente a Dios. Y como contrapartida antropológica que disponga a la oración, a la apertura a su palabra, a descubrirla y aceptarla por novedosa que sea en los signos de los tiempos y en los llamados al corazón del hombre. Pero debe también comunicar el contenido de ese misterio: el amor de Dios. Debe presentar a un Dios que es Padre cercano, bueno y salvador, que es en verdad Buena Noticia -recordatorio aparentemente super fluo, pero absolutamente necesario. $Y$ como contrapartida antropológica, que disponga al encuentro gozoso con ese Dios, a la confianza y a la esperanza. Al presentar a un Dios transcendente, pero que es Padre bondadoso y cercano, y a un Padre bondadoso que sigue siendo trascendente y misterio, la teología debe ayudar a que el hombre y los pueblos se encuentren con Dios, encuentro personal que no puede ser sustituido por ninguna doctrina ni por ninguna cultura.

Significa, en segundo lugar, que una teologia teologal debe desarrollar una teologia de la historia, pues ésta, como la espiritualidad, es necesario cuando la misma historia entra en crisis, se disgregan sus elementos anteriores y se necesitan nuevas sintesis. Además de las teologías de la historia bien elaboradas, la misma adjetivación de Dios y de Cristo la supone ya. La conciencia de la presencia de Cristo en las primeras comunidades o su espera inminente como el que ya viene y la puesta en suspenso de la parusia representan diversas teologias de la historia; lo mismo que el señorio triunfante de Cristo en una concepción eclesial de cristiandad y el humilde seguimiento de Jesús hacla el futuro absoluto de Dios. En América Latina, relacionar a Dios con liberación y cautiverio es ya en germen una teologia de la historia. Esta no se ha de- 
sarrollado todavia; pero la insistencia en el Dios de la vida - que la creación llegue a ser-, en el Dios de la liberacion - que el pecado sea superado-, en el Dios crucificado - la absoluta solidaridad de Dios con los oprimidos de este mundo-, y en el Dios que resucita a Jesús - la esperanza inconmovible de los pobres - ofrece sus elementos más importantes. Ofrece al menos ver la verdad de la historia desde Dios, proporcionarle su dirección más fundamental hacia la vida, olorgar sentido a quien se introduce en la historia desde su verdad para liberarla. Y como contraparida antropológica, la teologia de la historia debe of recer y exigir al hombre qué hacer con esa historia, de modo que la praxis no sea sólo una exigencia ética, sino teologal: hacer la historia según Dios.

En tercer lugar, una tcologia teologal tiene que ser trinitaria en su quehacer y en sus contenidos. Dios es de tal manera que no se le puede conocer sólo como pura alteridad con respecto al hombre, aunque lo sea infinitamente. El hombre tiene que encontrarse con Dios e introducirse en la realidad de Dios; eso es lo que posibilita y exige la realidad trinitaria de Dios. Por ello la teologia debe presentar a Dios como a quien se accede de diversas formas necesariamente complementarias: en la práctica del seguimiento de Jesús, en el caminar según el Espíritu, en estar ante Dios con gratuidad como el origen absoluto y el caminar hacia Dios con esperanza como el futuro absoluto. Tiene que presentar el problema o el misterio de Dios no sólo en la correlación intelectualista de verdad de Dios y razón del hombre, ni sólo en la correlación existencialista de sentido de Dios y decisión del hombre, sino en la correlación más amplia del saber, esperar y practicar, dentro de lo cual, si se hace como Jesús y con el espiritu de Jesús puede irse iluminando (u oscureciendo) el misterio de Dios.

Esa sintesis la puede ir haciendo la teología conceptualmente al mostrar cómo se remiten unos conceptos a otros según la revelación de Dios. Pero una síntesis dicente presupone que ya se ha hecho de alguna forma en el mismo quehacer teológico, en la unificación de su talante intelectual, esperanzado y práxico. De esa forma la leologia puede ayudar a que se realice la unidad en la que el saber, el esperar y el hacer se relacionan y se remiten mutuamente, y asi a responder y corresponder al Dios trinitario.

Una teología es toda ella espiritual, en cuanto teologal, cuando desde la experiencia de Dios y la ubicacion en la historia de Dios propone esa experiencia y cómo hacer la historia según Dios. Se trata de que la teologia ayude a responder y a corresponder al Dios que está pasando hoy por la historia. Si la teología no ayuda a que el espiritu del creyente esté a la altura del paso de Dios por la historia, hará muchas otras cosas buenas, pero no la fundamental y la más urgente hoy.

\subsection{Una teología popular}

La teologia debe hacerse dentro del pueblo de Dios y para el pueblo de Dios. De nuevo, es importante recordar y recalcar esta conocida verdad. Se trata de que la teologia sepa qué hacer con el pueblo de Dios. No basta para ello con tratar el pueblo de Dios como un contenido de la teología ni basta con recordar genéricamente que todo el pueblo de Dios es el sujeto de la fe y que no 
puede fallar en la verdad de la fe (LG 12). Se trata de que la teologia provenga de e introduzca en la realidad del pueblo de Dios y en la realidad de su fe, ilumine y anime al pueblo de Dios.

Esto no significa ignorar el cierto elitismo profesional del quehacer teológico, sino imbuir de espiritu popular ese quehacer sin dar la sensación de que el teblogo estuviera más allá de ese pueblo o fuera una especie de super-cristiano al cual debe referirse el pueblo de Dios, pero no a la inversa. Indudablemente la teologia puede y tiene que cumplir con algunas funciones especifica suyas como la de articular la fe del pueblo de Dios con la revelación, la tradición y el magisterio por una parte y con la situación histórica y sus ideologias por otra; adelantar sospechas sobre peligros de ideologizacion de la fe de ese pueblo; prever problemas futuros para esa fe y prepararla a dar respuestas adecuadas, etc. Todo eso debe hacer la teologia, pero no la exime de remitirse al pueblo de Dios y su fe para su constitución.

Esto quiere decir que la teologia debe tomar seriamente en cuenta y usar como una de sus fuentes de conocimiento la fe realizada del pueblo de Dios. En cuanto ésta es respuesta a la actual manifestación de Dios, ilumina lo que es la fe y lo que es Dios. Se trata de que dentro del circulo entre revelación y fe, ambas se iluminen mutuamente. Por ello para la teología son importantes los testimonios de la fe, no sólo en cuanto presentan una realidad que puede ser doctrinizada, sino en cuanto realidad que remite a la realidad de Dios. Estos testimonios pueden ser los de figuras señeras, pero también los de todo un pueblo o aquellos en que mejor se expresa la fe del pueblo de Dios. Por ello, como hace GG en su libro, hay que argumentar con los testimonios de la fe en la Escritura y en la tradición de la Iglesia, pero también con los testigos de la fe en el presente, con lo que son y dicen los santos y los mártires en la actualidad, con lo que son y dicen las comunidades, los sacerdotes, religiosas y obispos que están en contacto con ellas.

Esos testigos expresan los verdaderos y actuales problemas para la teologia, integran en sí mismos lo que se debe mantener desde el origen de la fe y lo que hay de novedoso en la respuesta de la fe, ayudan a redescubrir mejor lo que está en el origen de la le y apuntan a nuevas sintesis que la teología deberá elaborar.

El pueblo de Dios en América Latina y en muchas otras partes del mundo es un pueblo de pobres; por ello la teologia debe ser popular, no sólo formalmente en cuanto remitida al pueblo de Dios, sino más concretamente en cuanto remitida al pueblo pobre, el destinatario y correlato primario de la revelación de Dios. Entonces la teologia se hace verdaderamente popular, histórica y teológicamente. Esto significa que la teologia se hace parcial en cuanto a su ubicación y finalidad, pero que alcanza así también su verdadera universalidad. Pero entonces también - como Mons. Romero lo decia refiriéndose a la mision evangelizadora de la Iglesia - la teologia concreta novedosamente sus contenidos y redescubre a los que siempre han estado en la revelación. No se puede valorar suficientemente la importancia del pueblo pobre para que la teologia haya redescubierto contenidos teológicos tan importantes como el pe- 
cado que da muerte, la idolatria, la liberación, el evangelio como buena noticia, las bienaventuranzas y malaventuranzas, la actividad de los profetas de Israel, la denuncia de la injusticia, la relación entre práctica de la justicia y el conocimiento de Dios, el decisivo pasaje de Mi 25, etc., etc., y para concretar otros contenidos que ya se han revalorizado en otros lugares, pero que el pueblo pobre ha llenado con nuevos elementos como el discernimiento de los signos de los tiempos, la concepción de la Iglesia como Iglesia de los pobres, la cual asomó, pero que no cuajo todavía en el Vaticano II, el seguimiento de Jesús pobre, la cercanía a Jesús como el hermano mayor, el siervo de Jahvé como individuo y como todo un pueblo crucificado, la resurrección de Jesús como esperanza indestructible de los oprimidos, el Dios de la Vida, defensor y abogado de los pobres, el Espíritu de Dios capaz de dar vida, de hacer que quienes antes no eran ahora son personas con dignidad y pueblos conscientes, el reino de Dios como utopia transcendente, pero como realidad histórica a construir sin que la reserva escatologica relativice por igual todas sus expresiones históricas, etc. etc.

Este pueblo pobre de Dios en América Latina y en el tercer mundo se ha convertido en una carta de Dios a los hombres, a la lglesia y a la teología por lo que son y padecen, por lo que hacen y creen. Indudablemente no todo lo que ocurre dentro del pueblo de Dios es ya automáticamente manifestación de Dios y respuesta correcta de la fe; el mismo pueblo lo sabe y por ello una de sus actividades más frecuentes es el propio examen y la petición de conversión. Indudablemente también la teologia tiene que seguir teniendo en cuenta el polo originante de la revelación y de la fe, la Escritura; debe atender a la tradición y a lo que dice el magisterio sobre la novedad que va descubriendo y expresando el pueblo de Dios; debe tener en cuenta el diálogo intrateológico y el diálogo con las ciencias, filosofias e ideologías. Pero si la teologia no recurre también y principalmente al lugar de la realización de la fe del pueblo pobre estará mutilada, se hará una y otra vez abstracta y elitista - ahora en el sentido peyorativo del término-, y se privará de una insustituible fuente del conocimiento teológico. También la teología debe tomar seriamente en cuenta "el potencial evangelizador de los pobres" (Puebla, No. 1147); debe beber de su pozo, cuyas aguas iluminará y purificará, pero que no puede crear ni sustituir por medios puramente teológicos.

Esta teología popular es espiritual porque está imbuida del espiritu del pueblo pobre de Dios; con lo cual la teologia se hace solidaria y real. Una teología aislada del pueblo de Dios - y más si fuera contraria al pueblo de Dios-, que se alimenta sólo de si misma, da la sensación de irreal, aunque diga cosas verdaderas, y da la sensación de impotencia para superar esa irrealidad. Su superación acaece cuando la teología se hace en verdadera solidaridad con el pueblo de Dios; no sólo para estar a su servicio, sino dejándose inspirar por él. Entonces posee el espiritu del pueblo de Dios en el que vive el Espiritu de Dios. Que una teología espiritual sea popular quiere decir que esté a la altura del pueblo de Dios y del Espíritu que vive en él. 


\subsection{Una teologia creatural}

Una teologia espiritual debe ser hoy, y sobre todo hoy, una teología verdaderamente creatural, abierta al mundo y sus problemas, al hombre en general y al ser-hombre del creyente. No debe sacar del mundo, sutil o burdamente, al creyente y debe estar en disposición de apelar incluso a no creyentes o al menos a aquellos realmente interesados en hacer del mundo un mundo más humano y en vivir con sentido su propio ser-hombre.

Esto significa que la teología no debe comunicar la sensación de que el problema del ser-hombre ya está resuelto en principio y que lo que a ella le compete es una realidad, la cristiana, que le seria sobreañadida al ser-hombre del hombre. Indudablemente, la teologia tiene que repetir que el verdadero serhombre ha aparecido en Cristo y no puede renunciar a esta gozosa y escandalosa afirmación. Pero debe recalcar eficazmente que la fe cristiana remite al creyente a su ser-hombre y a la solidaridad con los hombres reales, con sus problemas y esperanzas reales.

Esto significa, por una parte, que la teología debe ser hecha con humildad y sin triunfalismos entre y ante los hombres de hoy. Con humildad, porque la teología no sabe en lo concreto mucho más que los demás hombres por tener una doctrina muy elaborada. Sabe - y cree- del amor de Dios y que en Jesús se ha manifestado el camino, la verdad y la vida. Esto le ofrece un modo fundamental de como ubicarse en la historia y la dirección que debe tomar la historia y por la que debe trabajar. Pero no le ahorra pasar por los interrogantes concretos de los demás hombres, por la búsqueda de soluciones concretas; no le ahorra hacerse las preguntas que se hacen los hombres honrados por el sentido de la historia, por un mundo actual donde la pobreza aumenta cuantitativamente y produce cada vez más millones de pobres, etc. La teología, con todo su aparato, pasa también por la soledad de que habla GG. Y sin triunfalismos, porque la teologia no es la única fuente del conocimiento de Dios en la Iglesia y porque ni siquiera la Iglesia en donde se hace teologia es el único lugar de la manifestación de Dios. Asi lo decía con claridad Mons. Romero: "La Iglesia cree que la acción del Espiritu que resucita a Cristo muerto en los hombres es más grande que ella misma. Más allá de los límites de la Iglesia hay mucha fuerza de la redención de Cristo; y los intentos libertarios de los hombres y de los grupos, aun sin profesarse cristianos, son impulsados por el Espiritu de Jesús. "22 La teología debe analizar lo que ocurre en la historia, las ideologias, los movimientos sociales "para purificarlos y animarlos e incorporarlos ...en el proyecto global de la redención cristiana," 23 como añade Mons. Romero; pero sin erigirse en árbitro distanciado e infalible, condenando a diestra y siniestra, como ocurre a veces, sin analizarse a si misma, sin ver lo que debe, de hecho, a veces a lo que critica del mundo. Tambièn la teología tiene su propia precaminosidad, tiene la concupiscencia a absolutizarse. Y por ello la teologia tiene que pasar por la conversión, examinarse a sí misma y dejarse verificar si en verdad es una teología para los hombres o para si misma.

Esta humildad de la teología es la que le permite ser creatural, cercana a los hombres reales y solidaria con ellos, lo que le permite hablarles desde cerca 
y no desde la distancia presuntuosa, con lo cual muchos hombres, en el primer mundo sobre todo, se han desentendido de la teologia y de la fe. En solidaridad con los hombres de hoy, una teologia creatural es en primer lugar honrada con la realidad tal cual es, de ella obtiene su agenda y no a la inversa y por ella es movida a revisar sus contenidos aunque le alejen de los ya poseidos. La honradez con lo real le es absolutamente necesaria para ser teologia en solidaridad con los hombres de hoy, pero también por su presupuesto último pues si se hace violencia a la verdad de las cosas, como nos avisa Pablo, éstas ya no manifiestan a Dios y el corazón del hombre, la luz de la teología, se entenbrece. $Y$ junto con la honradez, la fidelidad a la realidad y a sus exigencias. La teología debe acompañar a la realidad y no pretender. anacrónicamente lo contrario. Indudablemente debe discernir con los demás hombres como y hacia dónde la historia da más de si; dicho teológicamente, cómo y hacia dónde la historia se hace más historia de gracia y menos historia de pecado; pero debe evitar dar la impresión de que, suceda lo que suceda en la historia, su verdad permanece intocada por la historia. En lo fundamental esto es cierto; pero desentenderse de la historia seria ser infiel al presupuesto teológico del paso de Dios por la historia.

Una teologia hecha en verdad en solaridad con los hombres de hoy a la manera indicada le permite al menos la posibilidad de hablarles y de que éstos la escuchen. Entonces es cuando la teología puede decirles con credibilidad que el verdadero ser-hombre es ser creatura de Dios, puede of recerles el camino de Jesús como la realización del ser-hombre; que ese camino para nada los separa de la historia real, sino que los sumerge -más y mejor según la fe- en ella. Esta teologia creatural funge entonces como lo que tradicionalmente se ha llamado teología fundamental. Esta se ha llevado a cabo de diversas formas según los diversos retos para la fe en diferentes épocas y lugares. En la actualidad, la teología se hace teología fundamental cuando se convierte en invitacion y promesa. Ambas deberán contar con alguna racionalidad a priori, pero la racionalidad que of rece esta teologia creatural es a simultaneo; en la realizacion de lo que se ofrece. Si la teologia se hace con la humildad y solidaridad descrita, posee ya una cierta credibilidad; si ayuda a realizar la esperanza, si puede presentar testigos de ella, si ella misma es testimonial entonces puede quizás invitar a los hombres a recorrer el camino a Jesús y llegar así a ser hombres.

Para analizar una teologia toda ella espiritual se debieran haber analizado otras muchas cosas, quizás más importantes. Nos parece, sin embargo, que una teologia hecha radicalmente desde Dios, desde los pobres del pueblo de Dios y en medio de los hombres, tiene espíritu, está hecha y se ofrece con espiritu. En definitiva, esto lo hemos deducido, más que elucubrado, de las reacciones a la TL. No es solo ni principalmente un determinado método o unos contenidos novedosos los que explican el serio interés por esta teología, sino que al poner el dedo en la llaga de la realidad (Mons. Méndez de Almeida), al ofrecer la fe y el compromiso reales de miles de cristianos, ha tocado tambien el espiritu de muchos hombres. Muchos agradecen sinceramente el haberse reencontrado como creyentes y como seres humanos, el haber podido reconstruir el mosaico desperdigado de su fe y de su vida. 
Una teologia espiritual supone y expresa al paso del Espiritu del Señor en los corazones y en la historia. Muchos creen que eso es lo que está ocurriendo en América Latina y reconocerlo asi es ya un poderoso acto del espíritu. GG lo menciona en su libro; habla del tiempo propicio (p. 36) y con ello termina su libro:

Algo nuevo está naciendo, en medio de muchos y diversos sufrimientos, en América Latina. Eso es lo que ha llevado a hablar de un kairós, un tiempo propicio. Un momento en el que el Señor toca a las puertas de la comunidad eclesial que vive en el subcontinente y la invita a abrirle para cenar con ella (cf. Apoc 3,20) (p. 203).

\section{NOTAS}

1. Teologia y Espirilualidad, Selecciones de Teologia, XIII (1974) p. 142.

2. "Significado actual de Santo Tomás de Aquino," en varios, Teologia y mundo contemporaneo, edit. A. Vargas-Machuca, (Madrid, 1975) p. 36.

3. Zeit der Orden? Zur Mystik und Politik der Nochfolge, (Freiburg 1977).

4. G. Gutierrez, Beber en su propio pozo. En el itinerorio espiritual de un pueblo (Lima 1983), p. II.

5. Veánse los trabajos ya desde los inicios de la TL de S. Galilea, A. Paoli, E. Pirronio.

6. G. Gutiérrez, Teologio de la liberación (Lima, 1971), p. 254.

7. Ibid., p. 256.

8. Las revistas son Didlogo, Guatemala; Christus, Mexico; Mensaje, Santiago de Chile; Revista Eclesiástica Brasileira, Petrópolis, Brasil; Páginas, Lima, Perú; Estudios Centroamericanos, San Salvador, El Salvador; Sic, Caracas, Venezuela.

9. Christus 529-530, (1979-1980), p. 56.

10. Edit. Eduardo Bonin (San Jose 1982).

11. Ibid. p. 11.

12. Ibid. p. 13.

13. J. Espeja ha escrito recientemente "Liberación y Espirilualidad en America Latina," separata de Páginas, julio (1984), en donde presenta coda la teología de la liberación desde la espiritualidad aduciendo para ello 223 citas textuales de teblogos latinoamericanos. En otro libro reciente, Vida y Reflexion. Aportes de la teologla de la liberación al pensamiento teologico actual (Lima, 1983), G. Múgica reconoce la espiritualidad en el método, "El mtiodo teologico: una cuestion de espiritualidad," p. 21-43, y autores de varios continentes relacionan explicitamente la TL con la espiritualidad, "Exigencias de una nueva espiritualidad," p. 163. 248. Nog hay que desdeñar que la revisla Concilium pide a teblogos latinoamericanos aportes sobre espiritualidad, martirio, santidad, como en el número monográlico de marzo de 1983 ni que en la obra coleetiva Conceptos Fundamentales de la Pastoral (Madrid, 1983) el tema de la espiritualidad se le haya pedido a un autor latinoamericano, I. Ellacurla.

14. 1. Ellacuria, op. cit., p. 302.

15. Gustavo Gutiésrez, "Beber en su propio pozo," SIC marzo (1984), p. 122.

16. Sería muy prolijo cotejar las afirmaciones de GG con lo que ya han dicho otros teólogos latinoamericanos. Por ello mencionamos aqui algunos escritos más representativos de la espiritualidad. No mencionamos, por lo tanto, otros escritos sobre liberación, pobres, Dios, Iglesia de los pobres, Cristo liberador que realmente expresan y han preparado la explieitacion de la espiritualidad, pues la lista sería interminable. Entre elios pueden verse, Frei Betto, "Oraçao na aça. Contribuçao espiritualidade da libertacao." Suplement CEI, N. 18 (Rlo de Janeiro, 1977): "La oración una exigencia (también) politica, en Espiritualidad y Liberación en Américo Lasina, p. 15-26; L. Boff, La experiencia de Dios, 2a. ed. (Bogotá 1977); "Contemplativus in liberatione," Chrisius, S29-530 (1979-1980) p. 64-68; Vlo Crucis de la justicia, (Madrid, 1980); Vida segundo o Esplrito, (Petropolis, 1982); A. Cussianovich, "Praxis de liberacion. Camino de santidad," Diakonio, 6 (Managua, 1978), p. 70-79; "Espiritualidad eristiana y liberadora," "Christus, 531 (1980) p. 12-16; I. Ellacuría, "Fe y 
justicia," Christus, agosto y octubre (1977) p. 26-33 y 19-34; "Las bienaventuranzas como carta fundacional de la Iglesia de Is pobres," en varios, Iglesia de los pobres y organizociones populares, (San Salvador, 1979) p. 10S-118; "Espitilualidad," en varios, Concepios fundamentales de la pastoral, (Madrid, 1983); S. Galilea, Espiritualidad de la liberocion, (Santiago de Chile 1974), "La liberación como encuentro de la politica y de la contemplación, Concilium, 96 (1974), p. 313-327; "La espiritualildad de la liberación como espiritualidad politica," Christus, 499 (1977), p. 29-32; La religiosidad popu'ar como espiritualidod, (Madrid, 1979); Espiritualidad de la liberación según las bienaventuranzas, (Bogotá, 1979); "El rostro latinoamericano de la espiritualidad," Christus, 529-530 (1979-1980) p. 69-72 Renovación y espiritualidod (Bogotá, 1981); J.B. Libanio, "Acción y contemplación en nuestra situación confictiva," CIS, 25 (1977) p. 57.71; Discernimiento espiritual: reflexoes reologico-espirituais (Sao Paulo, 1977); J. H. Pico, "La oración en los procesos latinoamericanos de liberación," Chrisius, $529-530$ (1979-1980) p. 85-92; "El martirio hoy en América," Concilium, 183 (1984) p. 335-344; P. Richard, "La etica cristiana como espiritualidad liberadora en la realidad eclesial de América Latina," Cristianismo y Sociedad, 69 y 70 (1981) p. 51-59: "Espiritualidad para tiempos de revolución. Teología espiritual a la luz de San Pablo" en Espiritualidad y Liberación en América Latina, p. 87-101; J. Sobrino, "Espiritualidad de Jesús y de la liberación," Chrisfus, 529-530 (1979-1980) p. 59-63; "Experiencia de Dios en la Iglesia de los pobres," Cristianismo y sociedad, 63 (1980) p. 87-101: "Perfil de una santidad politica," Concilium, 103 (1983) p. 335-344; "Espiritualidad de la persecución y del martirio," Misiones Extranjeres, 75 (1983) p. 315-328; "Espiritualidad y liberación," Sal Terrae, 2 (1984) p. 139-162; P. Trigo, "Espiritualidad y cultura ante la modernizacion," Christus, 529-530 (1979-1980) p. 73-77. Habrla que afledir además los numerosos escritos sobre la vida religiosa y su espiritualidad.

17. Clr. L. Boff, Contemplativus in liberatione, p. 65; 1. Ellacuria, Fe y Justicia, p. 32.

18. El Dias de la vida, (Lima, 1981), p. 6.

19. Ibid., p. 7.

20. Contemplativus in liberatione, p. 64.

21. Espiritualidad para tiempos de revolución, p. 87.

22. "Iglesia y organizaciones pollticas populares. Tercera Carta Pastoral," en varios, La voz de los sin voz, (San Salvador, 1980) p. 113.

23. Ibid. 